\title{
Characterization of Cell Cycle Events in the Dark in Anacystis nidulans
}

\author{
By GERALD T. MARINO AND YUKIO ASATO* \\ Department of Biology, Southeastern Massachusetts University, North Dartmouth, \\ Massachusetts 02747, USA
}

(Received 7 June 1985; revised 16 December 1985)

Anacystis nidulans (Synechococcus PCC 6301) is an obligate phototrophic cyanobacterium. When light-grown cultures of Anacystis are transferred to the dark, the on going cell cycles are aborted. To characterize the fates of cell cycle events in the dark, synchronized cultures of $\boldsymbol{A}$. nidulans, taken at various phases of growth, were placed in the dark and the macromolecular contents and cell numbers were determined. Cell number did not increase in any culture in the dark. Protein and RNA contents remained the same. However, cultures in the last hour of their respective synthesis periods showed detectable increases in protein and RNA contents. In cultures in the early stages of DNA synthesis, no sustained increase in DNA was observed, indicating that DNA replication was not completed in the dark by these cultures. However, incorporation of ${ }^{32} \mathrm{P}$ in the DNA fraction in the dark suggested that DNA replication was completed for cultures in the last stages of DNA synthesis. These results suggest that macromolecular synthesis and cell septum formation were curtailed (with the exceptions indicated above) and further progress in the cell cycle stopped in the dark.

\section{INTRODUCTION}

When a light-grown exponential culture of Anacystis nidulans is placed in the dark for 12-24 h, the culture is synchronized upon re-exposure to the light (Asato \& Folsome, 1970). During the first $8 \mathrm{~h}$ after the dark to light shift, protein, RNA and DNA synthesis are sequentially initiated followed by cell septum formation, which is usually completed after $8 \mathrm{~h}$ (Asato, 1983). Subsequent cell cycles manifest the same sequences of cell events (Asato, 1979). Synchronized DNA synthesis within the synchronized cell cycle has been demonstrated in $A$. nidulans by others (Herdman et al., 1970; Herdman \& Carr, 1971; Delaney \& Carr, 1975; Gleason \& Ooka, 1978; Bagi et al., 1979). Phospholipid (Asato, 1979) and cell wall synthesis (Asato, 1984) and peak rates of $\mathrm{O}_{2}$ evolution (Csatorday \& Horvath, 1977) also occur at specific times within the cell cycle. It was concluded that the periods of macromolecular synthesis are major events in the cell developmental cycle of $\boldsymbol{A}$. nidulans and that these events are co-ordinately regulated (Asato, 1983).

A possible mechanism of induction of synchronized growth by dark incubation was suggested by Asato (1983). Dark incubation does not simply arrest the cell cycle but causes the ongoing cell cycle to abort. When dark-incubated cultures of $A$. nidulans are returned to light growth conditions, new cell cycles are reinitiated, as indicated by the sequential appearance of macromolecular synthesis. If the macromolecular synthesis periods (including cell wall and cell septum formation) are the major cell cycle events in $A$. nidulans, the stoppage of the cell cycle could be described in terms of the fates of these cell cycle events in the dark. Presently, there is conflicting evidence with regard to the extent of macromolecular metabolism in the dark in $A$. nidulans. No significant increase in the macromolecular contents and a reduced level of incorporation of radioactive precursors into protein, RNA, DNA and phospholipid fractions occur in the dark (Hayashi et al., 1969; Asato \& Folsome, 1970). Limited synthesis of protein and significant amounts of novel RNA species also occur (Doolittle \& Singer, 1974; Singer \& 
Doolittle, 1974). When cultures of $A$. nidulans (Göttingen strain) were first exposed to low light intensity and then to total darkness, RNA synthesis decreased during the low light but increased rapidly in the dark to the level before the shift in growth conditions; DNA increased at a low rate during the low light and dark conditions (Lorenzen \& Kaushik, 1976). Cell number increased significantly during the dark incubation period (Ssymank et al., 1977). Herdman et al. (1970) found increases of $19 \%, 22 \%$ and $15 \%$ in DNA, RNA and cell number, respectively, in $A$. nidulans in the dark in a $\mathrm{CO}_{2}$-free environment. In the reports mentioned above, metabolism of macromolecules was determined in exponential cultures placed in the dark. When synchronized cultures that had synthesized $50 \%$ of DNA in the light were subjected to $\mathrm{CO}_{2}$-free dark incubation conditions, the cells completed DNA replication but did not divide (Herdman \& Carr, 1971). These conflicting results could be attributed to the differences in the growth conditions or in the strains used. Because of the apparent differences in the extent of macromolecular metabolism in the dark by $A$. nidulans, we investigated the patterns of macromolecular contents and cell septum formation in synchronized cultures both in the light and after transfer to the dark.

\section{METHODS}

Organism and growth. Anacystis nidulans UTEX 625 (Synechococcus PCC 6301) was originally obtained from the Culture Collection of Algae, University of Texas, Austin, USA. The growth medium, conditions of growth, induction of synchronized growth and the quantitative methods for determination of protein, RNA (Ceriotti, 1955) and DNA (Keck, 1956) are described elsewhere (Asato \& Folsome, 1970; Asato, 1979).

Measurement of macromolecular contents in the dark. Synchronized cultures were placed in the dark at specified times after induction. At designated time intervals two samples $(20 \mathrm{ml})$ were removed and cell number and contents of protein, RNA and DNA were determined. Incorporation of ${ }^{32} \mathrm{P}$ in the DNA fraction was determined as described by Asato (1979).

\section{RESULTS}

\section{Macromolecular synthesis in synchronized growth}

The characteristics of synchronized growth were essentially the same as reported by Asato (1979) except that macromolecular synthesis periods were determined during the third cell division period (Fig. 1). Although synchronized growth of $A$. nidulans is characterized as partial synchrony, the pattern of cell division and macromolecular synthesis periods did not deteriorate significantly during the period from 14 to $22 \mathrm{~h}$ after the dark to light shift. In fact, synchronized cell division was observed up to the ninth cell division period when the proper dilutions were made to maintain the cell density of $1-4 \times 10^{7}$ cells $\mathrm{ml}^{-1}$ (unpublished results). Apparently, the pattern of synchronized growth could be sustained because of the presumed co-ordinated regulation of the cell cycle events (Asato, 1983).

\section{Fates of macromolecular metabolism and cell septum formation during the dark incubation period}

To characterize the fates of cell cycle events in the dark, samples of synchronized cultures from the mid-point of the second to the mid-point of the third cell division periods were analysed (Fig. 1). Cultures obtained during this cell growth cycle (hours 14-22) should be free of any effects of prior dark incubation. Cell septum formation is usually the last known event of the cell cycle. The 14 and $22 \mathrm{~h}$ samples contained the maximum distribution of cells that were involved in the process of cell septum formation. No significant increases in cell number were detectable in the dark for these samples, indicating that cell septum formation does not continue to completion. Cultures sampled during the periods of protein and RNA synthesis (up to the third hour of their respective synthesis periods) showed no detectable increase or decrease in protein or RNA content. However, cultures at the last stages of protein and RNA synthesis did show detectable increases (although not clearly evident in Fig. 1) of approximately $3.9 \%$ in protein content and $10 \%$ in RNA content. Although the amounts of protein and RNA detected were near or within the experimental errors of the method used, this pattern was observed in repeated experiments. 

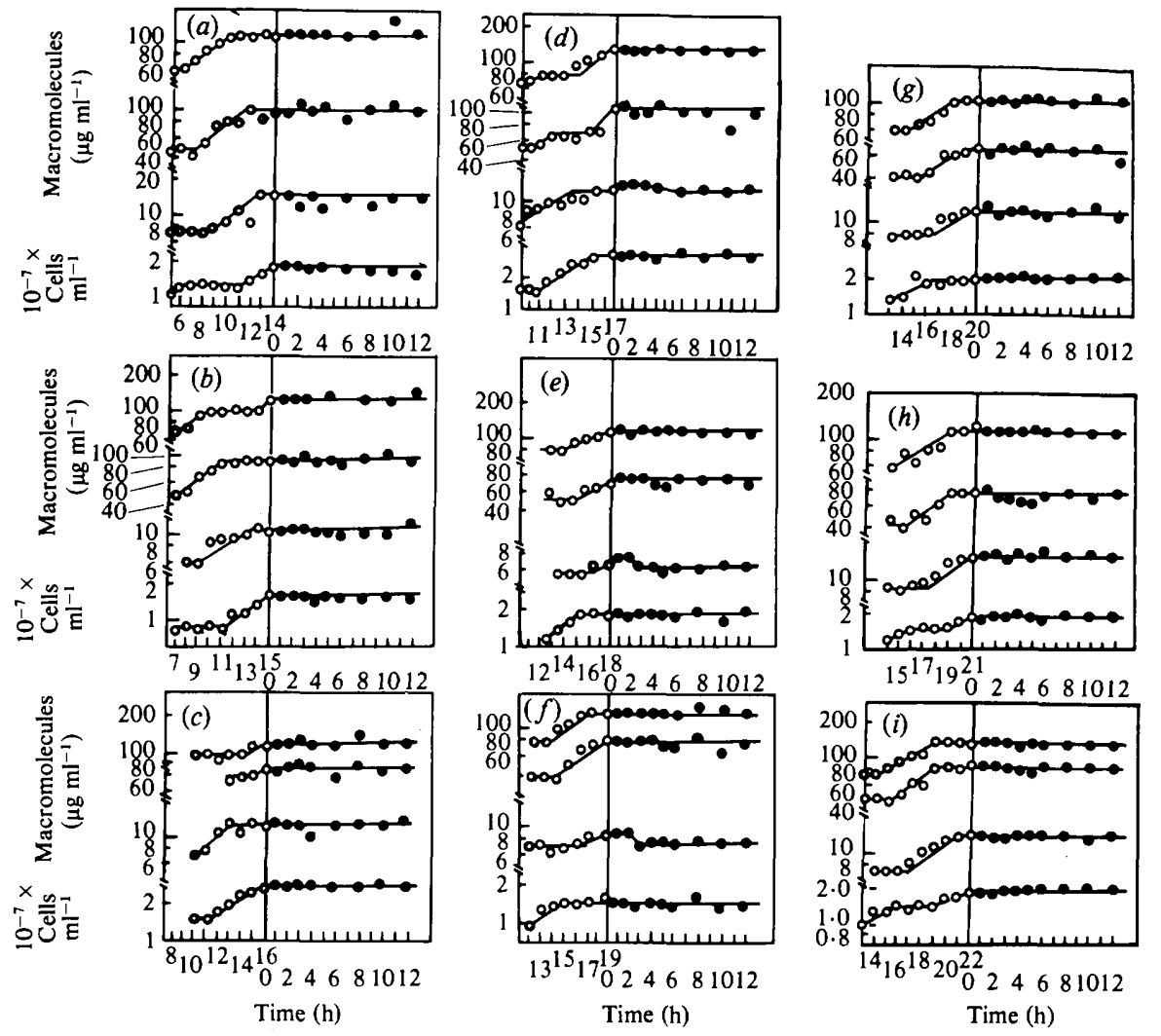

Fig. 1. Characterization of cell cycle events in the dark. $(a-i)$ The pattern of macromolecular contents and cell septum formation in the dark for cultures taken from synchronized growth at the times indicated in each figure. The vertical lines indicate the times when the light-grown synchronized cultures were placed in the dark. $\bigcirc$, Light-grown cultures; $O$, dark-grown cultures. The curves from top to bottom represent protein, RNA content, DNA content and cell number, respectively. The conditions of growth and methods of assessing macromolecules and total cell counts were as described by Asato (1979). Each figure represents an independent experiment.

The fate of replicating DNA during the dark incubation period cannot easily be interpreted. Cultures at the initial stages of DNA replication showed an initial increase followed by a plateau, a decrease and eventually a levelling of DNA content during the remaining portion of the incubation period. The increase calculated in terms of DNA content per cell was up to $10 \%$ while a decrease of as much as $15 \%$ of the DNA content per cell was detectable. The pattern of DNA measurements could be the result of experimental errors since increases or decreases in the DNA content measured were near the percentage error of $8.8 \%$ associated with the method utilized. Nevertheless, the pattern of DNA content shown in Fig. $1(d, e$ and $f)$ was observed in repeated experiments and may not, therefore, be the result of fortuitous alignment of experimental errors. In preliminary experiments, a synchronized culture in the DNA synthesis period was labelled with ${ }^{32} \mathrm{P}$ for $1 \mathrm{~h}$ and then placed in the dark for $12 \mathrm{~h}$. After the dark incubation period, decreases of radioactive labels in the DNA fractions of as much as $15 \%$ were observed for cultures in the first $3 \mathrm{~h}$ of the DNA synthesis period (Fig. 2). These results are consistent with the decrease in DNA content found in the present study although further experiments verifying and extending these results must be done in order to describe, without ambiguity, the fate of DNA replication in the dark. Nevertheless, cells in the early stages of DNA replication showed no evidence of completing DNA replication in the dark. Although 


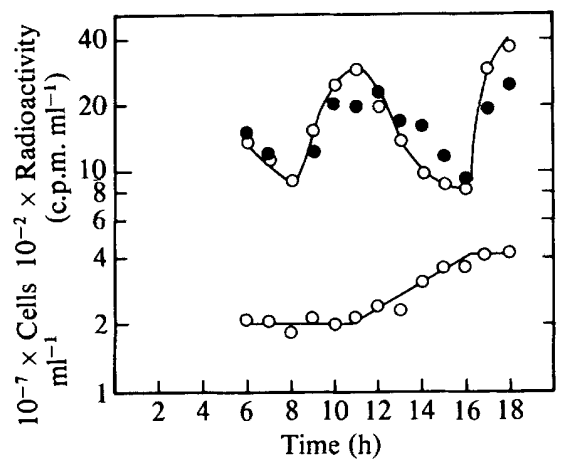

Fig. 2. Incorporation of ${ }^{32} \mathrm{P}$ in a synchronized culture during light and dark incubation. Samples of the synchronized culture were labelled with ${ }^{32} \mathrm{P}$ for $1 \mathrm{~h}$ at the times indicated. At the end of the labelling period duplicate $1 \mathrm{ml}$ samples were removed and the radioactivities $(O)$ in the DNA fraction were determined. The remaining culture was incubated for $12 \mathrm{~h}$ in the dark and then radioactivities $(O)$ in the DNA fraction were determined. The lower curve represents cell growth. The results are from a representative experiment.

samples taken after $3 \mathrm{~h}$ of DNA replication did not show any detectable change in DNA content during the dark incubation period (Fig. 1), the radioactive labelling study indicated that cells in the late stages of DNA replication could complete the replication in the dark (Fig. 2).

\section{DISCUSSION}

Dark incubation causes the ongoing cell cycle of $\boldsymbol{A}$. nidulans to abort (Asato, 1983) and, as a consequence, the demands for energy, reducing substances and precursors of macromolecules would be sharply decreased. In this background of reduced metabolic activities, metabolism of macromolecules should also be decreased. Indeed, protein and RNA content did not increase significantly in the dark although detectable increases were observed in the last stages of the protein and RNA synthesis periods. Septum formation is the last of the major cell cycle events, and was neither continued nor completed in the dark. The replicating DNA appeared to follow the same fate in the dark. If DNA replication did not continue to completion in the dark, it should be resumed in the light and the amount of DNA synthesized should be equivalent to that required to complete DNA replication. Such cultures, however, showed a doubling of the DNA content at the end of the DNA synthesis period, indicating that DNA replication was reinitiated from the origin of DNA replication (Asato, 1983). Moreover, DNA synthesis is preceded by protein and RNA synthesis and is followed by cell septum formation, which suggested that a new cell cycle was initiated in the light. If this interpretation is correct, the fate of the partially replicated DNA must be accounted for. One could theorize that it is removed by known enzymes present in the cells, resulting in the formation of a forkless circular genome.

A different pattern of DNA replication and cell growth in $A$. nidulans was reported by Herdman \& Carr (1971) during light and dark growth. When synchronized cultures that were in the mid-DNA synthesis period were placed in the dark, DNA synthesis was completed but the cells did not divide. Upon return to the light, the cells underwent one synchronized cell division (without DNA replication) but thereafter grew exponentially at a very low rate. It should be noted that there are significant differences in the growth conditions and the method of induction of the synchronized cultures. We are not able to explain at present the factors responsible for the differences in DNA replication in the dark observed by Herdman \& Carr (1971) and by ourselves. 


\section{REFERENCES}

Asato, Y. (1979). Macromolecular synthesis in synchronized cultures of Anacystis nidulans. Journal of Bacteriology 140, 65-72.

ASATo, Y. (1983). Dark incubation causes reinitiation of cell cycle events in Anacystis nidulans. Journal of Bacteriology 153, 1315-1321.

ASATo, Y. (1984). Characterization of cell cycle events in synchronized cultures of Anacystis nidulans. Journal of General Microbiology 130, 2535-2542.

Asato, Y. \& Folsome, C. E. (1970). Temporal genetic mapping of the blue-green alga, Anacystis nidulans. Genetics 65, 407-419.

Bagi, G., Csatorday, K. \& Farkas, G. L. (1979). Drifts in DNA level in the cyanobacterium Anacystis nidulans during synchrony induction and in synchronous culture. Archives of Microbiology 123, 109-111.

Csatorday, K. \& HoRvath, D. (1977). Synchronization of Anacystis nidulans, oxygen evolution during the cell cycle. Archives of Microbiology 111, 245-246.

Ceriotti, G. (1955). Determination of nucleic acids in animal tissues. Journal of Biological Chemistry 219, 59-70.

Delaney, S. F. \& CARR, N. G. (1975). Temporal genetic mapping in the blue-green alga Anacystis nidulans using ethyl methanesulphonate. Journal of General Microbiology 88, 259-268.

DoolitTle, W. F. \& Singer, R. A. (1974). Mutational analysis of dark endogenous metabolism in the bluegreen bacterium Anacystis nidulans. Journal of Bacteriology 119, 677-683.
Gleason, F. K. \& OoKa, M. P. (1978). Cell cycle and cell wall formation in Synechococcus sp., a unicellular cyanophyte. Cytobiologie 16, 224-234.

Hayashi, F., Ishida, M. K. \& KiKUChI, T. (1969). Macromolecular synthesis in a blue-green alga, Anacystis nidulans, in dark and light phases. Annual Reports of Research Reactor Institute, Kyoto University 2, 56-76.

Herdman, M. \& CarR, N. G. (1971). Observations on replication and cell division in synchronous cultures of the blue-green alga, Anacystis nidulans. Journal of Bacteriology 107, 583-584.

Herdman, M., Faulkner, B. M. \& Carr, N. G. (1970). Synchronous growth and genome replication in the blue-green alga, Anacystis nidulans. Archiv für Mikrobiologie 73, 238-249.

KECK, K. (1956). An ultramicro technique for the determination of deoxypentose nucleic acid. $A r$ chives of Biochemistry and Biophysics 63, 446-451.

LORENZEN, H. \& KAUSHIK, B. D. (1976). Experiments with synchronous Anacystis nidulans. Bericht der Deutschen botanischen Gesellschaft 89, 491-498.

Singer, R. A. \& Doolittle, W. F. (1974). Novel ribonucleic acid species accumulated in the dark in the blue-green alga, Anacystis nidulans. Journal of Bacteriology 118, 351-357.

Ssymank, K. V., Kaushik, B. D. \& Lorenzen, H. (1977). Synthesis of DNA during the cell cycle of synchronous Anacystis nidulans. Planta 133, 13-17. 